\title{
Different Analytical Methods of Para-Phenylenediamine Based Hair Dye
}

\author{
Hatem Abdel Moniem Ahmed ${ }^{1}$, Ragaa Mohamed Abdel Maaboud ${ }^{2}$, Fathy Fahim Abdul Latif ${ }^{3}$, \\ Adel Mohamed Kamal El-Dean ${ }^{4}$, Kamal Mohamed El-Shaieb ${ }^{3}$, Eugenio Vilanova ${ }^{5}$, Carmen Estevan $^{5}$ \\ ${ }^{1}$ Department of Forensic Chemistry, Faculty of Forensic Sciences, Naif Arab University for Security Sciences, Riyadh, Saudi Arabia; \\ ${ }^{2}$ Department of Forensic Medicine \& Clinical Toxicology, Faculty of Medicine, Assiut University, Assiut, Egypt; ${ }^{3}$ Chemistry De- \\ partment, Faculty of Science, Minia University, Minia, Egypt; ${ }^{4}$ Chemistry Department, Faculty of Science, Assiut University, Assiut, \\ Egypt; ${ }^{5}$ Institute of Bioengineering, Unit of Toxicology and Chemical Safety, University Miguel Hernández of Elche, Elche, Spain. \\ Email: Hatemahmed29@yahoo.com
}

Received May 20 $0^{\text {th }}, 2013$; revised June $22^{\text {nd }}, 2013$; accepted July $1^{\text {st }}, 2013$

Copyright (C) 2013 Hatem Abdel Moniem Ahmed et al. This is an open access article distributed under the Creative Commons Attribution License, which permits unrestricted use, distribution, and reproduction in any medium, provided the original work is properly cited.

\begin{abstract}
Many cases of toxicity and mortality either due to accidental or deliberate ingestion of hair dyes were reported in Egypt, Sudan, Israel, Morocco, Saudi Arabia, India and Tunisia. In the field of forensic analytical toxicology, the identification and quantification of chemicals are essential in deaths related to intoxication. The aim of the present study is to conduct chemico-analytical characterization of para-phenylenediamine (PPD) based hair dye of (Black stone hair dye, SHD) currently used for dying hear in Egypt, to confirm the identification of its components, that may be potentially toxic on oral or dermal exposure, this study uses comparison between different analytical methods. The applied analytical methods were inductively coupled plasma/MS (ICP/MS), witch used to determine the metal components of the dye, high performance liquid chromatography/MS (HPLC/MS) and gas chromatography/mass spectroscopy (GC/MS) were used for qualitative and quantitative analysis of PPD in the dye. A derivatization method was applied by transforming PPD (aromatic amines) into corresponding imine derivatives. This compound was prepared by condensation of 4-methylbenzeneamine with benzaldehyed to give N-benzylidene-4-methylbenzene-amine, which is a very stable internal standard. ICP/MS analysis revealed that most metal components of hair dye are Be, Na, Al, K, Ca, Sc, Ti, V, Cr, Mn, $\mathrm{Fe}, \mathrm{Cu}$, and $\mathrm{Zr}$, where HPLC/MS analysis revealed that PPD is the main ingredient of SHD. Derivatization is necessary for accurate determination of PPD in hair dye by GC/MS method and this results could not be obtained by direct injection of dye (without derivatization).
\end{abstract}

Keywords: PPD; PPD1; Stone Hair Dye; ICP; HPLC/MS and GC/MS

\section{Introduction}

Stone hair dye SHD is a commercial hair coloring. It contains PPD and other elements [1-3]. Many cases of toxicity and mortality either due to its accidental or deliberate ingestion were reported in Egypt, Sudan, Israel, Morocco, Saudi Arabia, India and Tunisia [4]. On the other hand, para-phenylenediamine is a very common allergen in man. Contact dermatitis following exposure to chemical allergens is a common health problem [5]. It is an immunologic skin reaction that occurs in a genetically predisposed individual, the risk of sensitization rises with frequency of contacts with the allergen. Cases of photosensitization induced by para-phenylenediamine have also been recorded. Some attributed this to hyper- sensitivity of its para-group [6]. N-Substitution of PPD influences its sensitization potential. Also the length of the chain of the alkyl substituent often has an effect on the sensitization potential [7].

A number of analytical procedures have been developed to separate and determine PPD intermediate in coloring products, including ICP/MS, HPLC/MS and GCMS [8,9]. Some of these methods require laborious and time consuming methods of extractions of hair dye components, followed by their chemical derivatization [10]. High performance liquid chromatography (HPLC) has been adopted as a popular method for the determination PPD derivatives, during which test chemicals are not heated above room temperature. Each PPD derivative has 
a characteristic ultraviolet absorption spectrum, and qualitative analysis is possible by selection of a suitable detection wavelength. Therefore HPLC is a suitable method for the determination of PPD derivatives [11]. HPLC/MS was chosen for the determination of PPD derivatives in the present study because of the stability of aromatic imines [12]. In the present work, PPD was converted into an imine; taking in account that coloring product compostion should not affect the reaction of PPD with aldehydes. On the application of GC/MS technique operating in SIM mode to determine the derivatives PPD obtained from commercially available hair dyes, many peaks were obtained in the chromatograms with the use of flame ionization detector. This could be due to the thermo labile nature of PPD. This explains the previous use of GC/MS for the qualitative analysis of its derivative [13].

The aim of the study is to define chemico-analytical characterization of PPD containing hair dye currently used in Egypt (SHD), identify the suitable methods of detection, and quantify its components that may be potentially toxic on oral or dermal exposure.

\section{Material and Methods}

\subsection{Chemicals}

A commercially available and widely used black hair dye in Upper Egypt, traditionally known as "Stone Hair Dye" (SHD) was obtained from market in Assuit. Para-phenylenediamine (PPD1) (CAS no. 106-50-3, 97\% pure), PPD2 (crystallization form of PPD1 99.9\%) and $\mathrm{H}_{2} \mathrm{O}_{2}$ were obtained from organic laboratory Faculty of Science Assuit University. Sodium tetraborat (Ponreac Quimica SA, Espain), Methanol (Lichrosolv, HPLC grad > 99.8\% pure), Second water (was obtained using a Milliq system with Q-PAK Purification Paks (Millipore Corp., Bedford, MA)\} obtained from the unit of toxicology and chemical safety, institute of bioengineering, University Miguel Hernández of Elche (Alicante) Spain. Hydrochloric acid (37\%) was obtained from Merck KGaA (Darmstadt, Germany). Benzaldehyde (+99\%, chlorine free) was purchased from Sigma-Aldrich (Milan, Italy). Tetrahydrofuran (THF) (Merck, Darmstadt, Germany).

\subsection{Apparatuses and Instruments}

Inductively coupled plasma-mass spectrometry 7700 (ICP-MS) Brochure, from (Agilent Technologies Inc., Palo Alto, CA, USA).

High performance chromatography (HPLC-MS), the column used was XDB-phenyl, $4.6 \times 150 \mathrm{~nm}$, and 3.5 micron, from (Agilent Technologies Inc., Palo Alto, CA, USA).

Gas chromatography/mass spectroscopy (GC/MS) (GC 6890 N, MS 5973 N) analyses was performed using a GC/MS system G1800 Series II (Agilent Technologies Inc., Palo Alto, CA, USA), equipped with an HP-5MS (30 m $\times 0.25 \mathrm{~mm}$, Ph Mesiloxane 5\%) capillary column.

\subsection{Preparation Injection of the Samples for Injection}

\subsubsection{ICP-MS}

Two samples of SHD were weighted and dissolved in second water. The first was $0.1 \mathrm{mg} / \mathrm{ml}$, and the second was $3.3 \mathrm{mg} / \mathrm{ml}$. The used blank was second water. Tuning solution was used to adjust the instrument. Samples were injected directly to the instrument. Each sample repeated three times and the average was taken.

\subsubsection{HPLC/MS}

Preparation of Mobil phase:

Borate buffer: 19.06 gm of Sodium tetraborat was dissolved in $800 \mathrm{ml}$ distilled water and completed to 1000 $\mathrm{ml}$ to reach to $\mathrm{pH} 8.0$ using $0.1 \mathrm{~N} \mathrm{HCl}$.

Preparation of the samples of PPD1, PPD2 \& SHD for injection:

- $10 \mathrm{mg}(10000 \mu \mathrm{L})$ of PPD and (SHD) were dissolved in $10 \mathrm{ml}$ of (30\% Methanol and 70\% buffer).

- Samples were centrifuged at 7500 rcf for 5 min.

- $200 \mu \mathrm{L}$ of the supernatant were filtered using nylon millex $(0.45 \mu \mathrm{L})$.

- $100 \mu \mathrm{L}$ from the last pure solution were diluted to $1000 \mu \mathrm{L}$ using $900 \mu \mathrm{L}$ (30\% Methanol and 70\% buffer, the concentration of this solution was 0.1 $\mathrm{mg} / \mathrm{ml}(1 / 10)$.

- $500 \mu \mathrm{L}$ from the last solution was diluted to $1000 \mu \mathrm{L}$ using $500 \mu \mathrm{L}$ (30\% Methanol and 70\% buffer. The concentration of this solution was $0.05 \mathrm{mg} / \mathrm{ml}$ (1/500).

The apparatus was adjusted at the following parameters:

- flow rate $0.05 \mathrm{ml} / \mathrm{min}, 125$ bar

- Solvent A is 70\% Borate buffer at pH 8

- Solvent B is 30\% Methanol

- Stop time is 9 min

- Wavelength $242 \mathrm{~nm}$

Three samples of PPD1, PPD2 and SHD were analyzed and each sample was repeated three times. The summation of all samples was 27 runs and the average of readings was taken.

\section{GC-MS}

\subsection{Derivatization of Hair Dye SHD \& PPD (Original Solution)}

3.1.1. Preparation of the $\mathbf{N}^{1}, \mathbf{N}^{4}$-Dibenzylidenebenzene1,4-diamine (Derivatized SHD and PPD)

$975.6 \mathrm{mg}$ Benzaldehyde (9.20 mmol) was added to a magnetically stirred solutions of PPD and SHD (497.1 $\mathrm{mg}, 4.60 \mathrm{mmol})$ in THF (20 ml). The resulting mixture 
was treated with a catalytic amount of 4-methylbenzenesulfonic acid (23.74 mg, $0.138 \mathrm{mmol}$ ) and then $\mathrm{Na}_{2} \mathrm{SO}_{4}$ (236.13 mg, $18.4 \mathrm{mmol}$ ) was added as drying agent. After $5 \mathrm{~h}$ at $70^{\circ} \mathrm{C}$, the reaction mixture was filtered and the solvent was evaporated under vacuum, to give a yellow oil which was dissolved in $\mathrm{CHCl}_{3}(2 \mathrm{ml})$. Using $\mathrm{CHCl}_{3} / \mathrm{MeOH}(9: 1, \mathrm{v} / \mathrm{v})$ as eluent, and visualizing the spot of residual benzaldehyde with a $5 \%$ solution of 2 , 4-dinitrophenylhydrazine in ethanol (99.5\%), the product was recovered in $81 \%$ yield after precipitation from $n$ hexane $(15 \mathrm{ml})$. The purity of the final compound was checked by ${ }^{1} \mathrm{H}$ NMR.

\subsubsection{Preparation of the Samples for Injection}

The original solution was diluted 100 times by taking 50 $\mu \mathrm{l}$ of it and adding $4.95 \mathrm{ml}$ of THF, so the final concentration was $5 \mathrm{mg} / \mathrm{ml}$. Second dilution was obtained by taking $50 \mu \mathrm{l}$ from the first dilution and adding $4.95 \mathrm{ml}$ of $\mathrm{THF}$, so the final concentration is $0.05 \mathrm{mg} / \mathrm{ml}$.

The GC/MS analyses were carried out in splitless mode (1 min purge off) using helium as carrier gas at a flow rate of $1 \mathrm{ml} / \mathrm{min}$. The injection port temperature was $250^{\circ} \mathrm{C}$ for derivatization PPD and PPD, the oven was maintained at an initial temperature of $60^{\circ} \mathrm{C}$ for 2 min for PPD and derivatized PPD, and then programmed at $14^{\circ} \mathrm{C} / \mathrm{min}$ for PPD and derivatized PPD to a final temperature of $280^{\circ} \mathrm{C}$ and stop time for PPD but for derivatized PPD, it was maintained for $20 \mathrm{~min}$.

\subsection{Injection of PPD without Derivatization}

Four concentrations were prepared $(10 \mu \mathrm{g}, 30 \mu \mathrm{g}, 50 \mu \mathrm{g}$ and $100 \mu \mathrm{g}$ ) of PPD and SHD, they were injected in GCMS and each concentration was repeated three times, so the total was 18 runs.

\section{Results}

\subsection{Inductively Coupled Plasma-Mass Spectrometry (ICP/MS)}

Table 1 showed the analysis of SHD at different concentrations. At concentration $100 \mu \mathrm{g} / \mathrm{ml}$, some elements were detected in different concentrations as $\mathrm{Al} 0.12 \mu \mathrm{g} / \mathrm{ml}, \mathrm{K}$ $1 \mu \mathrm{g} / \mathrm{ml}$, Sc $0.003 \mu \mathrm{g} / \mathrm{ml}, \mathrm{V} 0.003 \mu \mathrm{g} / \mathrm{ml}$, Cr $0.023 \mu \mathrm{g} / \mathrm{ml}$, Mn $0.006 \mu \mathrm{g} / \mathrm{ml}$ and Fe $0.6 \mu \mathrm{g} / \mathrm{ml}$, while elements as Be, $\mathrm{Na}, \mathrm{Ca}, \mathrm{Ti}, \mathrm{Cu}$ and $\mathrm{Zr}$ could not be detected. By increasing the concentration of SHD to $(3.3 \mathrm{mg} / \mathrm{ml})$, the concentration of elements increase as, Al $0.36 \mu \mathrm{g} / \mathrm{ml}, \mathrm{K} 2.0$ $\mu \mathrm{g} / \mathrm{ml}$, Sc $0.04 \mu \mathrm{g} / \mathrm{ml}, \mathrm{V} 0.005 \mu \mathrm{g} / \mathrm{ml}$, Cr $0.526 \mu \mathrm{g} / \mathrm{ml}$, Mn $0.016 \mu \mathrm{g} / \mathrm{ml}$ and Fe $0.8 \mu \mathrm{g} / \mathrm{ml}$ and some elements could be detected as $\mathrm{Ca} 0.36 \mu \mathrm{g} / \mathrm{ml}$ and $\mathrm{Cu} 0.01 \mu \mathrm{g} / \mathrm{ml}$.

In regards to SHD concentration of $10 \mathrm{mg} / \mathrm{ml}$, new elements appeared as Be $2.65 \mu \mathrm{g} / \mathrm{ml}$, Na $21.2 \mu \mathrm{g} / \mathrm{ml} \mathrm{Ti}$ $0.008 \mu \mathrm{g} / \mathrm{ml}$ and $\mathrm{Zr} 0.023 \mu \mathrm{g} / \mathrm{ml}$, where other elements values increased, Al $1.4 \mu \mathrm{g} / \mathrm{ml}, \mathrm{K} 6.0 \mu \mathrm{g} / \mathrm{ml}$, Ca 4.9 $\mu \mathrm{g} / \mathrm{ml}$, Sc $0.096 \mu \mathrm{g} / \mathrm{ml}, \mathrm{V} 0.203 \mu \mathrm{g} / \mathrm{ml}$, Cr $1.464 \mu \mathrm{g} / \mathrm{ml}$, $\mathrm{Mn} 0.018 \mu \mathrm{g} / \mathrm{ml}$ and $\mathrm{Fe} 1.7 \mu \mathrm{g} / \mathrm{ml}$ and $\mathrm{Cu} 0.025 \mu \mathrm{g} / \mathrm{ml}$.

\subsection{Qualitative and Quantitative Analysis of SHD by HPLC/MS}

4.2.1. Qualitative Analysis (Detection of PPD in SHD) The retention time for PPD in SHD was $4.57 \mathrm{~min}$ and it was the same retention time of standard PPD1, PPD2, as shown in Figures 1, 2, and 3.

\subsubsection{Quantitative Analysis (Detection of PPD in SHD)}

The concentration was calculated using the peak height:

By the use PPD1, It was fond that, the concentration of PPD in SHD was $97.54 \%$.

Table 1. The elemental components of SHD at different concentrations.

\begin{tabular}{cccc}
\hline Element & SHD $\mathbf{1 0 0} \mathbf{\mu g} / \mathbf{m l}$ & SHD 3.3 $\mathbf{~ g} / \mathbf{m l}$ & SHD 10 $\mathbf{~ m} / \mathbf{m l}$ \\
\hline $\mathrm{Be}$ & 0.000 & 0.000 & 2.650 \\
$\mathrm{Na}$ & 0.000 & 0.000 & 21.20 \\
$\mathrm{Al}$ & 0.120 & 0.360 & 1.400 \\
$\mathrm{~K}$ & 1.000 & 2.000 & 6.000 \\
$\mathrm{Ca}$ & 0.000 & 3.600 & 4.900 \\
$\mathrm{Sc}$ & 0.008 & 0.040 & 0.096 \\
$\mathrm{Ti}$ & 0.000 & 0.000 & 0.008 \\
$\mathrm{~V}$ & 0.003 & 0.005 & 0.203 \\
$\mathrm{Cr}$ & 0.023 & 0.526 & 1.464 \\
$\mathrm{Mn}$ & 0.006 & 0.016 & 0.018 \\
$\mathrm{Fe}$ & 0.600 & 0.800 & 1.700 \\
$\mathrm{Cu}$ & 0.000 & 0.010 & 0.025 \\
$\mathrm{Zr}$ & 0.000 & 0.000 & 0.023 \\
\hline
\end{tabular}

Element Conc. With $\mu \mathrm{g} / \mathrm{l}$. 


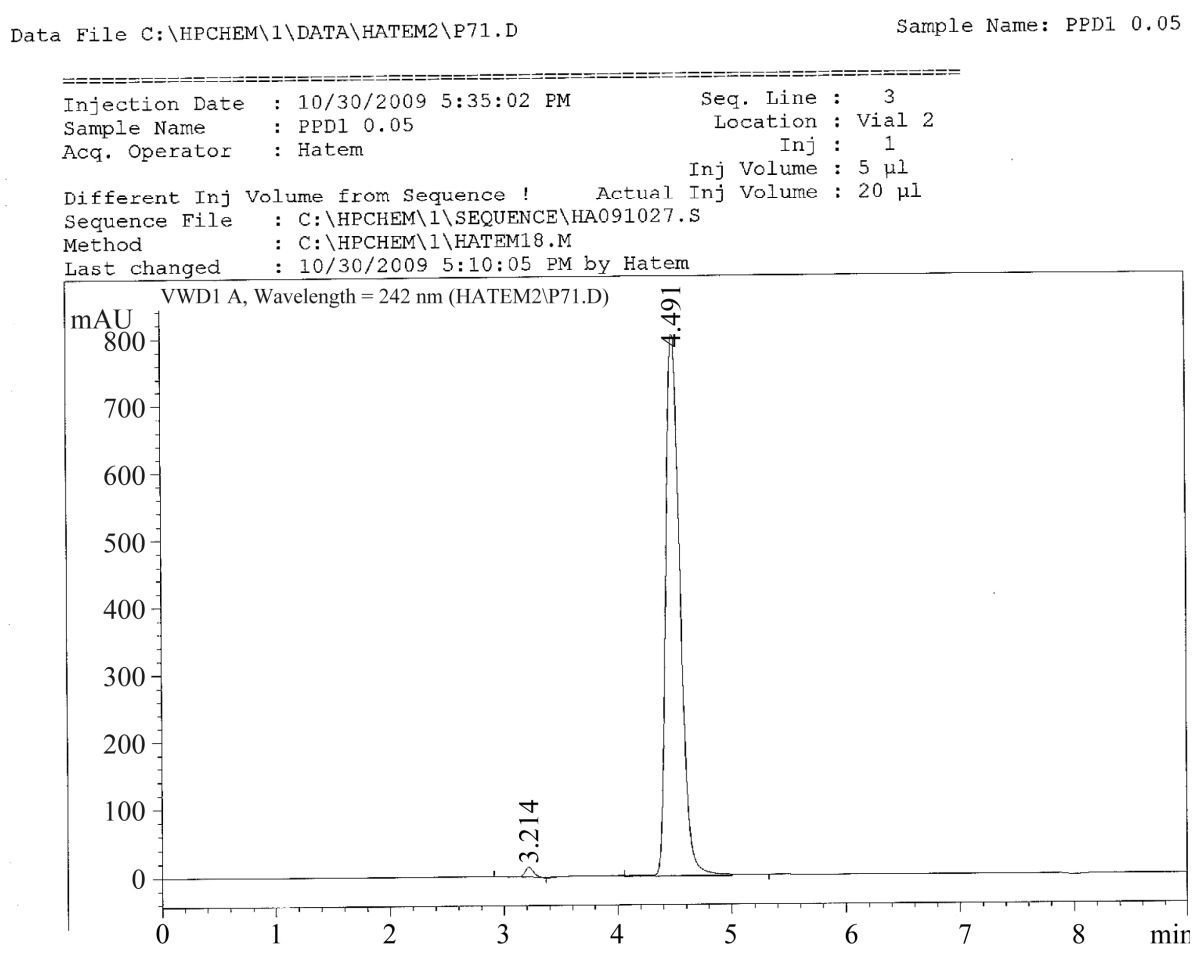

Figure 1. Ultraviolet absorption spectrum of PPD1 in methanol/borate.

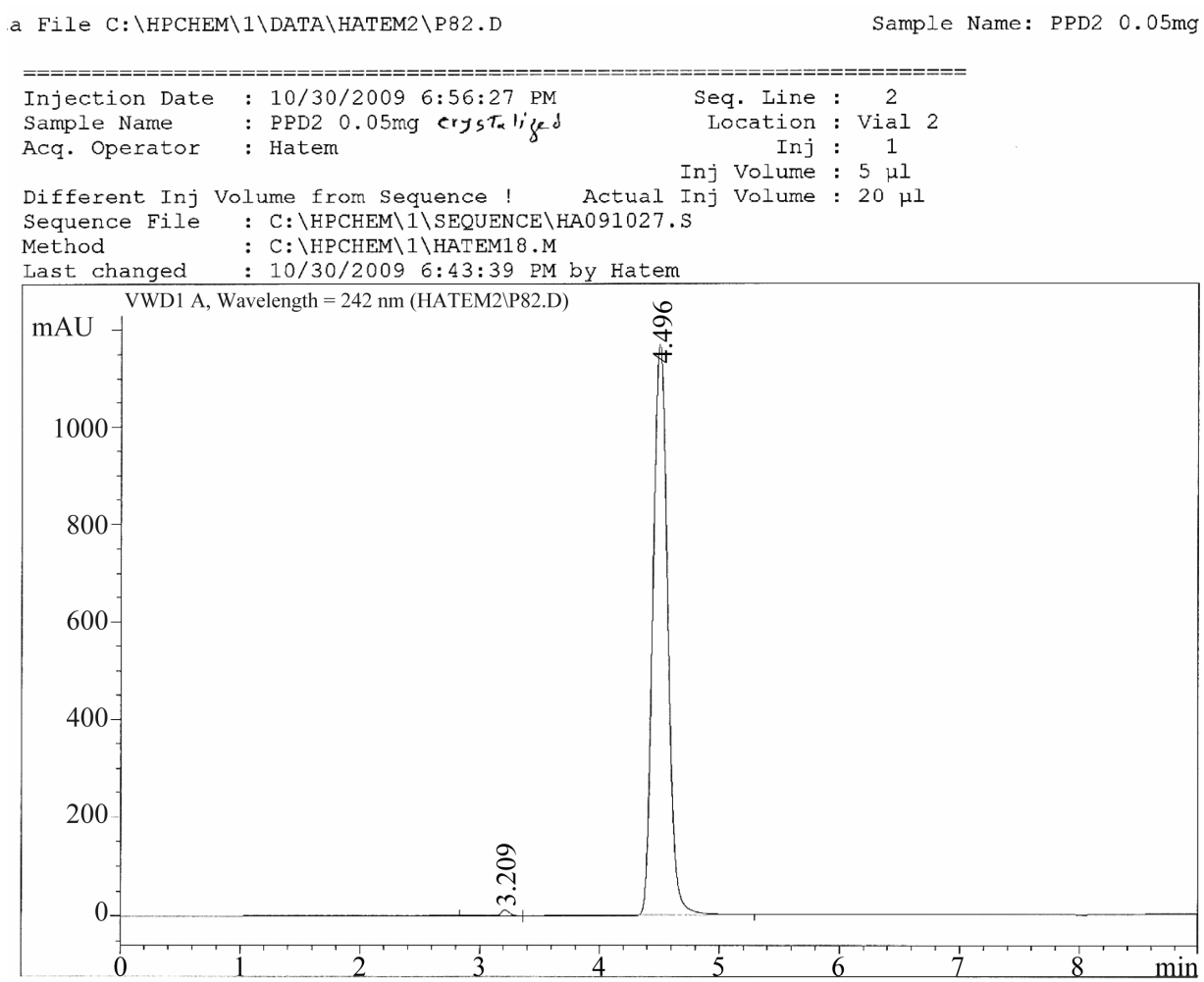

Figure 2. Ultraviolet absorption spectrum of PPD2 in methanol/borate.

By the use of PPD2, it was fond that, the concentration of PPD in SHD was 99.9\%.

The concentration calculated using area:
By the use of PPD1, it was fond that, the concentration of PPD in SHD was 99.66\%, while by the use of PPD2, the concentration of PPD in SHD was100.03\%, Table 2. 


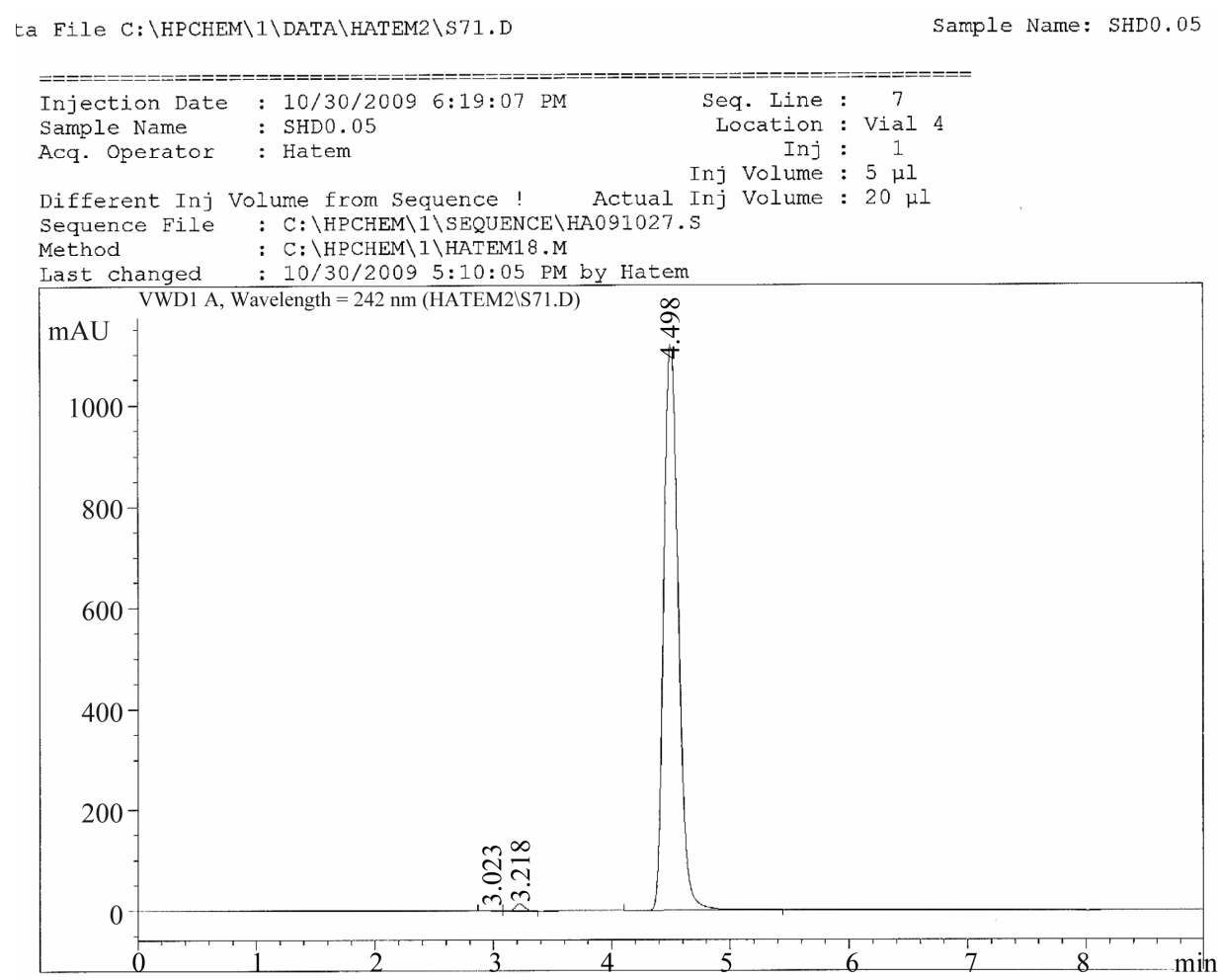

Figure 3. Ultraviolet absorption spectrum of SHD in methanol/borate.

\subsection{Qualitative and Quantitative Analysis of SHD by GC/MS}

\subsubsection{Using Direct Injection of PPD and SHD without Derivatization by GC/MS}

1) Qualitative analysis

The retention time for PPD in SHD was $5.65 \mathrm{~min}$, it was the same retention time in standard PPD, and the mass spectra at 108 Mwt for PPD in SHD was the same as the standard PPD, as shown in Figures 4, 5.

2) Quantitative analysis

At concentrations of $10 \mu \mathrm{g}, 30 \mu \mathrm{g}, 50 \mu \mathrm{g}$ and $100 \mu \mathrm{g}$, the concentration of PPD in SHD were $3 \mu \mathrm{g}, 15.7 \mu \mathrm{g}$, $17.56 \mu$ g and 31.56.

\subsubsection{Using Indirect Injection of PPD and SHD with Derivatization}

1) Qualitative analysis:

- For derivatized PPD

${ }^{1} \mathrm{H}$ NMR $\left(\mathrm{CDCl}_{3}\right), \delta$ (ppm): 7.29 - 7.31 (m, $4 \mathrm{H}$; Ar-H), 7.46 - 7.52 (m, 6 H; Ar-H), 7.90 - 7.95 (m, 4 H; Ar-H), 8.52 (s, $2 \mathrm{H} ; \mathrm{HC}=\mathrm{N})$.

- For derivatized SHD

${ }^{1} \mathrm{H}$ NMR $\left(\mathrm{CDCl}_{3}\right), \delta$ (ppm): 7.29 - 7.31 (m, $4 \mathrm{H}$; Ar-H), 7.46 - 7.52 (m, 6 H; Ar-H), 7.90 - 7.95 (m, 4 H; Ar-H), 8.52 (s, 2 H; HC=N), as shown in Figure 6.

- For derivatized PPD

GC/MS (EI): 284 [ $\left.M^{+}, 100 \%\right] ; 283$ (40); 207 (9); 180 (5); 77 (7)
Table 2. The Conc. of PPD in SHD using average area.

\begin{tabular}{cccc}
\hline & Average & SD & Conc. of PPD in SHD \% \\
\hline PPD1 & 99.23 & 0.058 & 99.66 \\
PPD2 & 95.67 & 5.312 & 103.03 \\
\hline
\end{tabular}

- For derivatized PPD

GC/MS (EI): 284 [M $\left.M^{+}, 100 \%\right] ; 283$ (40); 207 (9); 180 (5); 77 (7).

2) Quantitative analysis

The concentration of PPD in SHD at concentrations 5 $\mathrm{mg} / \mathrm{ml}$ and $500 \mathrm{mg} / \mathrm{ml}$ were $0.922 \mathrm{mg}$ and $417.89 \mathrm{mg}$ but for $0.05 \mathrm{mg} / \mathrm{ml}$ there is no signal for PPD and SHD.

\section{Disscussion}

Many studies reported the occurrence of hazardous health effects as a result of the use of "black hair" dyes or "black henna" either through its cosmetic use or through occupational exposure as in barbers. Mutagenic, carcinogenic, cataractogenic, hypersensitivity and hematopoietic disorders have been reported as consequences of hair dye use $[14,15]$. In the field of forensic analytical toxicology, the identification and quantization of chemicals are essential in deaths related to intoxication. In the present study, Stone hair dye was analyzed by different methods to identify its components and to verify the suitable method of their determination.

In a previous study, SHD analysis by Energy Disper- 


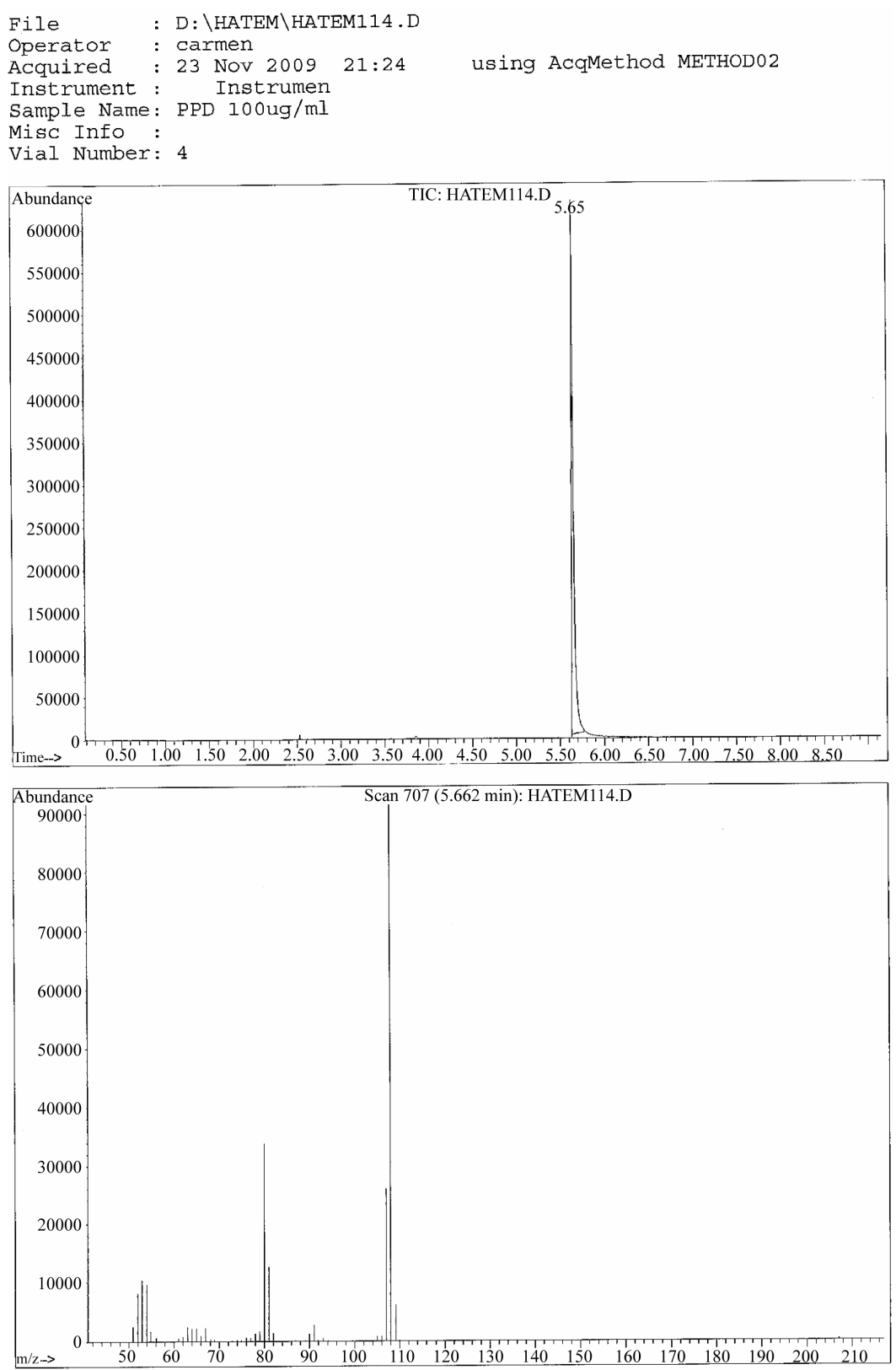

Figure 4. Retention time of PPD using GC/MS.

sive X-ray (E.D.X.) microanalysis revealed the following, Al 55.12\%, Si 11.37\%, S 1.47\%, Fe 4.61\%, Cu 16.61\%, Zn $10.07 \%$, Sb $0.73 \%, \mathrm{~Pb} 0.91 \%, \mathrm{~K} 0.52 \%$, and Sc 0.3715 . By comparing the previous results with ICP-MS results in present study, it was noticed that Aluminum $(1.4 \mu \mathrm{g})$ represented the second highest component after $\mathrm{Cr}(1.464 \mu \mathrm{g})$ in SHD, but $\mathrm{Cr}, \mathrm{Na}, \mathrm{Be}, \mathrm{Ca}, \mathrm{Ti}, \mathrm{V}, \mathrm{Zr}$ and Mn components were not detected in E.D.X. analysis, on the other hand, the following components Si, S, Zn, Sb and $\mathrm{Pb}$ not detected in ICP/MS (Table 1). This may be attributed to the difference in the origin of the dye or due to the deference in devices sensitivity.

High performance liquid chromatography HPLC/MS has been adopted as a popular method for the determination of PPD. Each PPD derivative has a characteristic ultraviolet absorption spectrum, and qualitative analysis is possible by selection of a suitable detection wavelength [16]. The chromatograms of PPD1, PPD2 showed one characteristic peak at retention time between 4.49 min and $4.50 \mathrm{~min}$, (Figures 4 and 5) where the chromatogram (Figure 6) showed the retention time of SHD is between $4.49 \mathrm{~min}$ and $4.50 \mathrm{~min}$ as the same retention time of standard PPD1, PPD2. This confirms that PPD is the main component of SHD and it could be used as an indicator of its presence in screening analysis of samples. The determination of PPD1, PPD2 and SHD were carried 

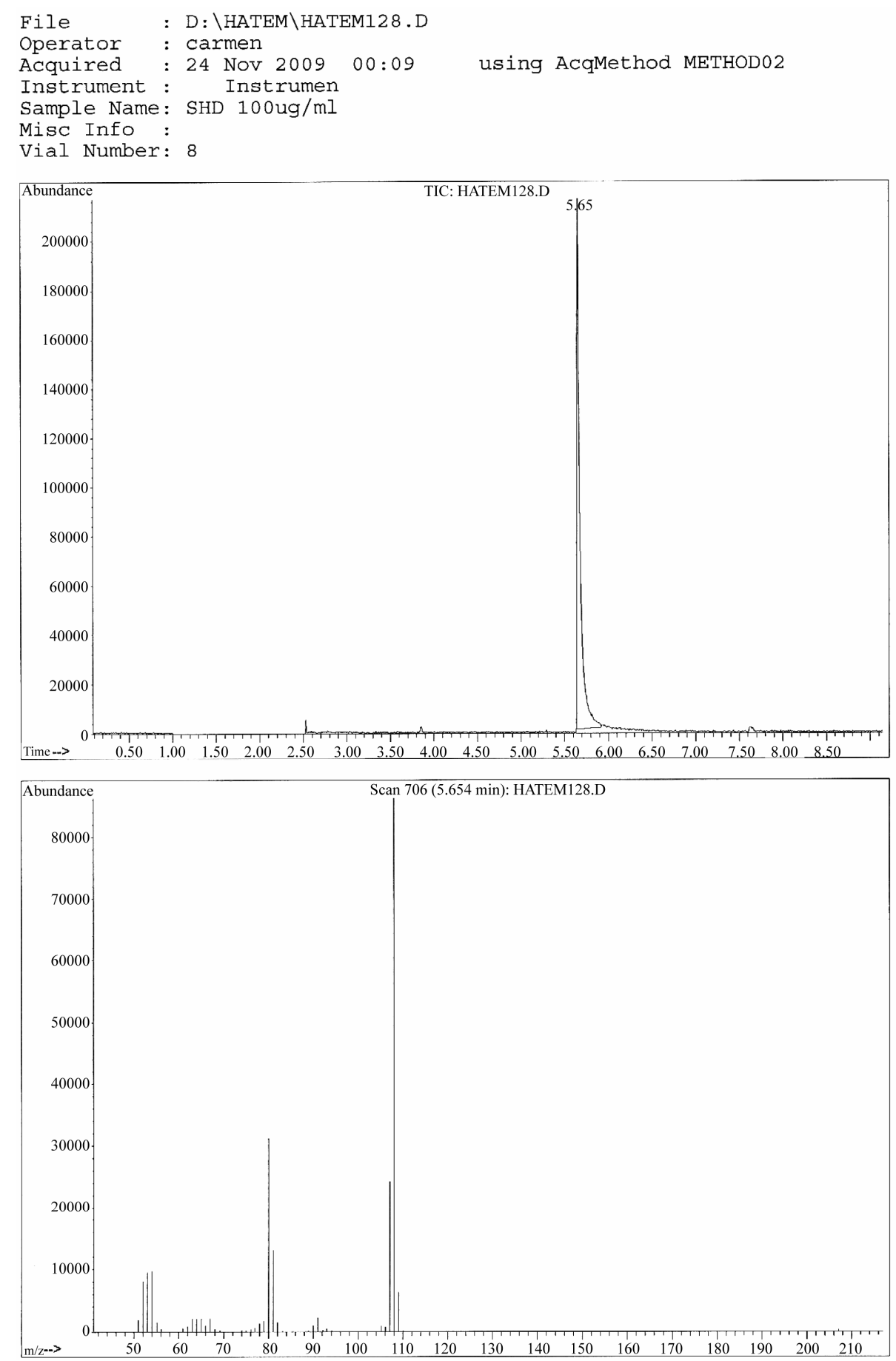

Figure 5. Retention time of SHD using GC/M.

out using total average area [17]. In the present results, it was found that $99.66 \%$ of SHD was PPD1 and $100.03 \%$ of it was PPD2, from previous results, the concentration of PPD in SHD by using the average aria of PPD1 and PPD2 was $99.85 \%$, so we can say that the concentration of metals was $0.155 \%$, this means that SHD mainly PPD. GC/MS was previously used in qualitative analysis of PPD [18]. By direct injecting SHD gave retention time at
5.65, which was the same retention time of stan- dard PPD, this means that PPD is the mean component of SHD but the quantity couldn't be determined by direct injection of sample (without derivatization). Certain analyses, specifically nitrogen containing compounds (i.e., aliphatic primary, secondary, and tertiary amines), can be difficult to detect using GC because there is significant adsorption of the basic amines on the often acidic column 


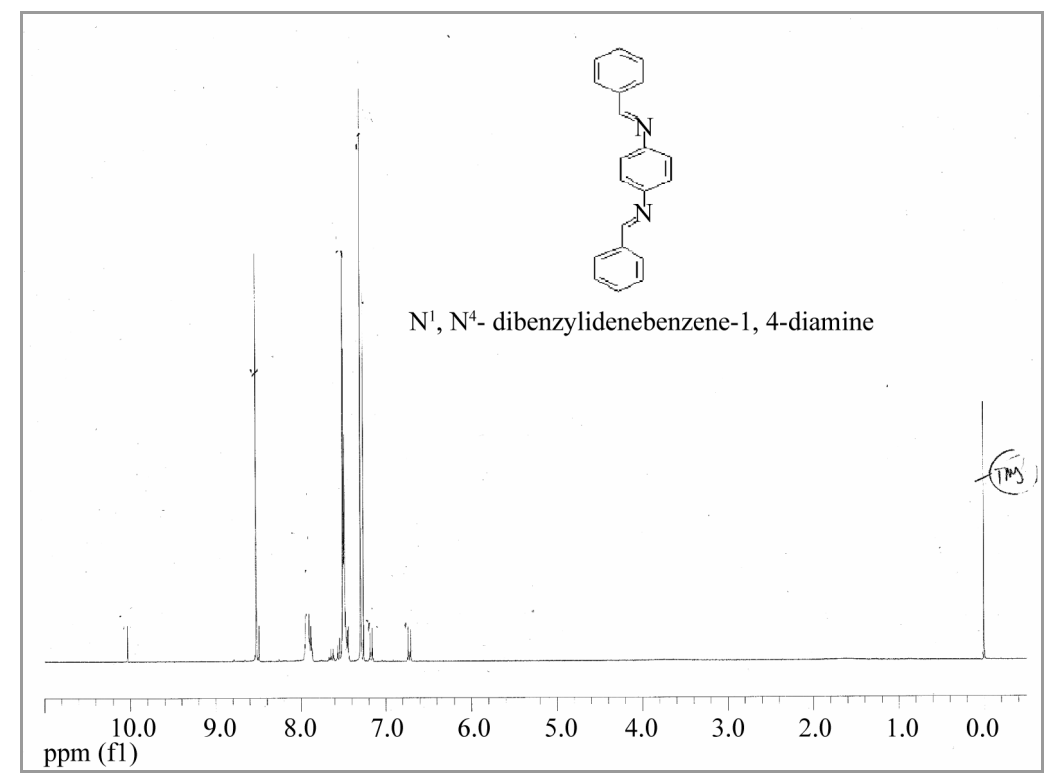

Figure 6. ${ }^{1} \mathrm{H}$ NMR for derivatized SHD for derivatized PPD.

as well as decomposition of the analyte [19]. Organic amines need to be derivatized before GC analyses [20]. So we modified a method (derivatization) that gives us a thermo stable compound, which gave us more accurate quantitative results. In the present experiment, a method for detecting PPD as one peak was modified using splitless mode, which gave characteristic one peak. The analytical technique GC/MS in SIM mode, was applied to determine the concentration levels of PPD in hair dyes, this requires complete derivatization of this intermediate to enhance the instrumental response [21]. In analogy to the hair dyeing process, a complete derivatization of PPD could be performed by a stable imine, because the content and composition of the coloring products should not affect the reaction with an aldehyde. Therefore, benzaldehyde was chosen as the best reactant to prepare imine derivatives from PPD, and the very good stability generally observed for aromatic imines [22], and very efficient protocol for the determination of PPD in commercial hair dyes. In the present experiment, the splitless mode was used for PPD as a sensitive and accurate analytical method for the determination of PPD in commercial hair dyes. The results, showed good linearity for the recovery of PPD and high levels of sensitivity, this recommend the use of the proposed method for the quantification of PPD in all commercially available hair dyeing products.

\section{Conclusion}

ICP analysis provides an accurate method for determination of metal components of hair dye, where HPLC analysis revealed that PPD is the main ingredient of SHD. Derivatization is necessary for accurate determination of PPD in hair dye by GC/MS method and this results could not be obtained by direct injection of dye (without derivatization).

\section{REFERENCES}

[1] L. S. Cook, K. E. Malone, J. R. Daling, L. F. Voigt and N. S. Weiss, "Hair product use and the risk of breast cancer in young women," Cancer Causes and Control, Vol. 10, No. 6, 1999, pp. 551-559. doi:10.1023/A:1008903126798

[2] C. Nagata, H. Shimizu, K. Hirashima, E. Kakishita, K. Fujimura, Y. Niho, M. Karasawa, S. Oguma, Y. Yoshiday and H. Mizoguchi, "Hair Dye Use and Occupational Exposure to Organic Solvents as Risk Factors for Myelodysplastic Syndrome,” Leukemia Research, Vol. 23, No. 1, 1999. pp. 57-62. doi:10.1016/S0145-2126(98)00135-0

[3] M. Gago-Dominguez, J. E. Castelao, J. M. Yuan, M. C. $\mathrm{Yu}$ and R. K. Ross, "Use of Permanent Hair Dyes and Bladder-Cancer Risk,” International Journal of Cancer, Vol. 91, No. 4, 2001, pp. 575-579. doi:10.1002/1097-0215(200002)9999:9999<::AID-IJC10 $\underline{92>3.0 . C O, 2-S}$

[4] M. Hashim, Y. O. Hamza, B. Yahia, F. M. Khogali and G. I. Sulieman, "Poisoning from Henna Dye and Para-Phenylenediamine Mixtures in Children in Khartoum," Annals of Tropical Paediatrics, Vol. 12, No. 1, 1992, pp. 3-6.

[5] C. K. S. Pease, "From Xenobiotic Chemistry and Metabolism to Better Prediction and Risk Assessment of Skin Allergy,” Toxicology, Vol. 192, No. 1, 2003, pp. 122. doi:10.1016/S0300-483X(03)00246-4

[6] GDCh-Advisory Committee on Existing Chemicals of Environmental Relevance, BUA Report 97, 1992.

[7] Y. Ikarashi, K. Ohno, J. Momma, T. Tsuchiya, A. Nakamura, "Assessment of Contact Sensitivity of Four Thiourea Rubber Accelerators: Comparison of Two Mouse Lymph Node Assays with the Guinea Pig Maximization Test," Food and Chemical Toxicology, Vol. 32, No. 11, 
1994, pp. 1067-1072. doi:10.1016/0278-6915(94)90148-1

[8] V. Andrisano, R. Gotti, A. M. Di Pietra and V. Carrini, "HPLC Analysis of Oxidation Hair Dyes in Permanent Hair Colorants," Journal of Liquid Chromatography, Vol. 17, No. 13, 1994, pp. 2919-2937. doi:10.1080/10826079408013510

[9] N. Suresh and C. Rastogi, “A Method for the Analysis of Intermediates of Oxidative Hair Dyes in Cosmetic Products,” Journal of Separation Science, Vol. 24, No. 3, 2001, pp. 173-178.

doi:10.1002/1615-9314(20010301)24:3<173::AID-JSSC1 73>3.0.CO,2-L

[10] N. Tanada, M. Kaegura, K. Hara, Y. Hieda, M. Takamoto and S. Kashimura, "Demonstration of Oxidation Dyes on Human Hair,” Forensic Science International, Vol. 64, No. 1, 1994, p. 1-8. doi:10.1016/0379-0738(94)90237-2

[11] Y. Kawamura, M. Miura, T. Sugita and T. Yamada, "Residue and Release of Antioxidants and Ultraviolet Stabilizers in Polyethylene Products in Contact with Foodstuffs," Journal of the Food Hygienic Society of Japan, Vol. 38, No. 1, 1997, pp. 27-33. doi:10.3358/shokueishi.38.27

[12] M. L. Di Gioia, A. Le Pera, A. Liguori, A. Leggio, C. Siciliano and G. Sindona, "Highly Stereoselective Synthesis of Optically Pure C-Aryl Imines from $\alpha$-L-Amino Acid Methyl Esters.," Synthetic Communication, Vol. 33, No. 24, 2003, pp. 4331-4338.

[13] F. Denizot and R. Lang, "Rapid Colorimetric Assay for Cell Growth and Survival. Modifications to the TetraZolium Dye Procedure Giving Improved Sensitivity and Reliability," Journal of Immunological Methods, Vol. 89, No. 2, 1986, pp. 271-277.

[14] A. Shibata, R. Sasaki, N. Hamajima and K. Aoki, "Mortality of Hematopoietic Disorders and Hair Dye Use among Barbers,” Nippon Ketsueki Gakkai Zasshi, Vol. 53, No. 1, 1990, pp. 116-118.

[15] A. Ashar "Acute Angioedema in Paraphenylenediamine
Poisoning” Journal of Pakistan Medical Association, Vol. 53, No. 3, 2003, pp. 120-122.

[16] K. Modha, J. P. Whiteside and R. E. Spier, “The Determination of Cellular Viability of Hybridoma Cells in Microtitre Plates: A Colorimetric Assay Based on Neutral Red," Cytotechnology, Vol. 13, No. 3, 1993, pp. 227-232. $\underline{\text { doi:10.1007/BF00749819 }}$

[17] Y. Ikarashi and M. Kaniwa, "Determination of p-Phenylenediamine and Related Antioxidants in Rubber Boots by High Performance Liquid Chromatography. Development of an Analylical Method for N-(1-Methylheptyl)N'-Phenyl-p-Phenylenediamine," Journal of Health Science, Vol. 46, No. 6, 2000, pp. 467-473.

[18] J. E. Coligan, A. M. Kruisbeek, D. H. Margulies, E. M. Shevach and W. Stober, "Measurement of Tumor Necrosis Factor A and B,” In: R. Coico, Ed., Current Protocols in Immunology, John Wiley and Sons, Inc., New York, 1996.

[19] H. Kataoka, "Derivatization Reactions for the Determination of Amines by Gas Chromatography and Their Applications in Environmental Analysis," Journal of Chromatography A, Vol. 733, No. 1-2, 1996, pp. 19-34.

[20] E. H. Soufleros, E. Bouloumpasi, A. Zotou and Z. Loukou, "Determination of Biogenic Amines in Greek Wines by HPLC and Ultraviolet Detection after Dansylation and Examination of Factors Affecting Their Presence and Concentration,” Food Chemistry, Vol. 101, No. 2, 2007, pp. 704-716.

[21] R. Ghosh, N. Nadiminty, J. E. Fitzpatrick, W. L. Alworth, T. J. Slaga and A. P. Kumar, "Eugenol Causes Melanoma Growth Suppression through Inhibition of $\mathrm{E}_{2} \mathrm{~F}_{1}$ Transcriptional Activity," The Journal of Biological Chemistry, Vol. 280, No. 7, 2005, pp. 5812-5819. doi:10.1074/jbc.M411429200

[22] A. B. Tiku, S. K. Abraham and R. K. Kale, "Ugenol as an in Vivo Radioprotective Agent," Journal of Radiation Research, Vol. 45, No. 3, 2004, 45, pp. 435-440. 